УДК 628.16.098.4:663.25.013

\title{
ОБОСНОВАНИЕ ВЫБОРА АНАЭРОБНОГО БИОРЕАКТОРА ДЛЯ ОЧИСТКИ СТОЧНЫХ ВОД ПРЕДПРИЯТИЙ ПЕРВИЧНОГО ВИНОДЕЛИЯ
}

\author{
(C) Г. В. Крусир, И. Ф. Соколова
}

В работе рассмотрены вопросы анализа наиболее подходящуей конструкции анаэробного биореактора для сбраживания сточных вод предприятий первичного виноделия. Дана сравнительная оценка существующих конструкций анаэробных биореакторов на основе следующих характеристик: нагрузка по органическому веществу, гидравлической время сбраживания субстрата, степень очистки, температура сбраживания, объем образованного биогаза и срок ожидаемой окупаемости.

Ключевые слова: виноделие, стоки, биогаз, метаногенез, биореактор.

The work provides an insight into the issues of analysis of the most suitable design of bioreactor for anaerobic fermentation of wastewater of the initial wine-making enterprises. The comparative description analysis of existent reactors intended for fermentation of the effluents produced by fermentation enterprises, was performed on the base on the following characteristics: load of organic matter, while the hydraulic fermentation substrate, the degree of purification, fermentation temperature, the volume of biogas formed and expected payback period. Keywords: wine, wastewater, biogas, methanogenesis, bioreactor.

\section{1. Введение}

В связи с постоянно растущими темпами развития промышленности возникает проблема поддержания экологической чистоты. Как известно, пищевая промышленность, в результате производственных процессов, образует разные по качественному и количественному составу сточные воды, состав которых особенно сложен на предприятиях первичного виноделия. Для эффективного очищения стоков виноделия, в последнее время, все чаще используют анаэробные методы сбраживания с получением биогаза. Для организации эффективного метанового брожения сточных вод следует учитывать не только факторы, обеспечивающие стабильность протекания процесса и максимальную эффективность очистки, но и конструкцию биореактора.

\section{2. Постановка проблемы}

Сточные воды предприятий первичного виноделия характеризуются высоким содержанием органических веществ (ХПК 10-20 г/л, БПК 5-15 г/л), которые представляют серьезную угрозу для окружающей среды, в связи с чем проблема ее очистки, обеззараживания и утилизации особенно актуальна.

На сегодняшний для эффективного решения проблемы утилизации концентрированных сточных вод первичного виноделия используют анаэробные методы очистки с использованием метантенков (анаэробный биореактор). Метантенки должны выбираться дифференциально, с учетом количественного и качественно состава сточных вод.

\section{3. Литературный обзор}

В настоящее время интенсивно развивается технологии анаэробной обработки промышленных стоков, применяемые в основном для высококонцентрированных сточных вод. Бурное развитие анаэробной техники связано со стремлением создавать компактные и эффективные аппараты, отличающиеся надежностью, эффективностью очистки, низкими капитальными, эксплуатационными и энергетическими затратами на очистку сточных вод. Развитие анаэробной техники происходило от примитивных смесителей, анаэробных контактных аппаратов к анаэробным фильтрам и современным UASB и EGSB реакторам. В мировой практике за последние 10-15 лет анаэробные реакторы второго поколения стали основными сооружениями для очистки высококонцентрированных сточных вод, обеспечивая эффективную очистку стоков в очень широком диапазоне концентраций (БПК $=0,3-100$ г/л), с временем пребывания воды в аппаратах от 30 мин. до 48 ч.

Обработка высококонцентрированных сточных вод в анаэробных условиях, по сравнению с аэробной очисткой, позволяет снизить капитальные затраты почти в 10 раз, разместить сооружения на значительно меньшей площади (приблизительно в 10-20 раз). При этом эксплуатационные расходы, по сравнению с аэробной очисткой, снижаются практически в три раза $[1,2]$. Недостатки анаэробного метода, связанные с низкой скоростью роста анаэробных бактерий, их высокой чувствительностью к изменению $\mathrm{pH}$, температуры и колебаниям концентраций загрязнений в сточной воде, по сравнению с аэробными. Существенным преимуществом анаэробного метода является уменьшение количества избыточного ила (в 3-10 раз), его стабильность, а также возможность получения дополнительной энергии за счет образующегося биогаза.

Наиболее общепринятая классификация анаэробных реакторов основана на форме макроструктур метаногенной биомассы в них. По этому принципу все конструкции можно разделить на реакторы со взвешенно-седиментирующей биомассой (илом) и прикрепленной биомассой (биопленкой) [3, 4]. Основными представителями современных реакторов являются: 
- реактор с восходящем потоком жидкости через слой анаэробного ила (UASB);

- реактор с расширенным и взвешенным слоем гранул (EGSB);

- перегородочный реактор (ABR);

- биофильтр с восходящим потоком (AF);

- гибридные реакторы, сочетающие в себе конструкции двух реакторов (например: AF и AFB, HABR);

- биофильтр с нисходящем потоком жидкости и неподвижно закрепленной биопленкой (DSFF);

- реактор с псевдоожиженным слоем носителя (AFB) и др. [5-7].

Анаэробный метод применяется для очистки самых разнообразных сточных вод и, в первую очередь, для целлюлозно-бумажной промышленности и бродильных производств.
4. Обоснование выбора типа анаэробного биореактора для сбраживания сточных вод винодельческих предприятий

Эффективность процесса очистки сточных вод и получения биогаза зависит от правильно подобранной конструкции биореактора. Основополагающими критериями выбора конструкции биореактора для обработки сточных вод предприятий первичного виноделия должны быть: эффективность удаления химического потребления кислорода (ХПК), нагрузка по органическому веществу на м $^{3}$ реактора в сутки, а так же капитальные, эксплуатационные и энергетические затраты. Ниже в табл. 1 представлена сравнительная характеристика анаэробных биореакторов.

Таблица 1

Сравнительная характеристика анаэробных биореакторов

\begin{tabular}{|c|c|c|c|c|c|c|}
\hline $\begin{array}{c}\text { Тип } \\
\text { реактора }\end{array}$ & $\mathrm{T},{ }^{\circ} \mathrm{C}$ & $\begin{array}{l}\text { ГВУ, } \\
\text { сут }\end{array}$ & 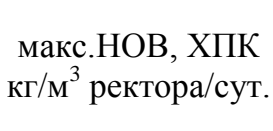 & $\begin{array}{c}\text { Выход } \\
\text { биогаза, } \mathrm{m}^{3} / \mathrm{M}^{3} \\
\mathrm{p}-\mathrm{pa} / \mathrm{cyт.}\end{array}$ & $\begin{array}{c}\text { Эффективность } \\
\text { удаления } \\
\text { ХПК,\% }\end{array}$ & $\begin{array}{c}\text { Срок } \\
\text { окупаемости }\end{array}$ \\
\hline UASB & $35-37$ & $6-8$ & 16 & $2,0-2,5$ & $85-93$ & 3,5 \\
\hline ABR & $35-37$ & $12-15$ & 15 & $2,0-2,3$ & $80-85$ & 4 \\
\hline $\mathrm{AF}$ & $35-37$ & $10-12$ & 20 & $1,8-2,1$ & 50-55 & 4 \\
\hline HABR & $35-37$ & $12-14$ & 21 & $1,5-2,0$ & $70-80$ & 5 \\
\hline DSFF & $35-37$ & $11-14$ & 20 & $1,8-2,3$ & $70-75$ & 4,5 \\
\hline AFB & $35-37$ & 9-12 & 11 & $2,1-2,5$ & $70-80$ & 6 \\
\hline
\end{tabular}

Согласно данным, представленным в табл. 1 можно сделать вывод, что одними из наиболее подходящих конструкций являются UASB-реакторы, так как они обладают высокой степенью очистки стока, порядка 93 \% от начального значения ХПК, стабильны при высоких нагрузках по органическому веществу, что крайне важно, так как сточные воды первичного виноделия содержат почти $95 \%$ органических веществ, при этом выход биогаза достигает 2,0-2,5 $\mathrm{m}^{3} / \mathrm{M}^{3}$ реактора/сут. Таким образом, UASB-реактор является стабильной системой с высокой эффективностью удаления органических веществ, обладающей большим запасом прочности и высокой генерацией биогаза.

Исследование эффективности снижения значения ХПК в UASB-реакторе представлено на рис 1.

Согласно представленному графику эффективность процесса очистки сточных вод достигает $92 \%$ на 4 сутки метаногенеза.

Исследование процесса выхода биогаза в UASB-реакторе представлено на рис. 2.

Результаты проведенных исследований позволяют сделать вывод что, процесс образования биогаза начинается через 22 часа после загрузки субстрата, однако содержание метана в нем равно нулю, по мере увеличения выхода биогаза увеличивается и содержания метана. Максимальный выход биогаза наблюдался на 21 сутки и составил 5,65 дм $^{3} /$ сут, при содержании метана $67 \%$. При сжигании биогаза наблюдалось стабильное голубое пламя.

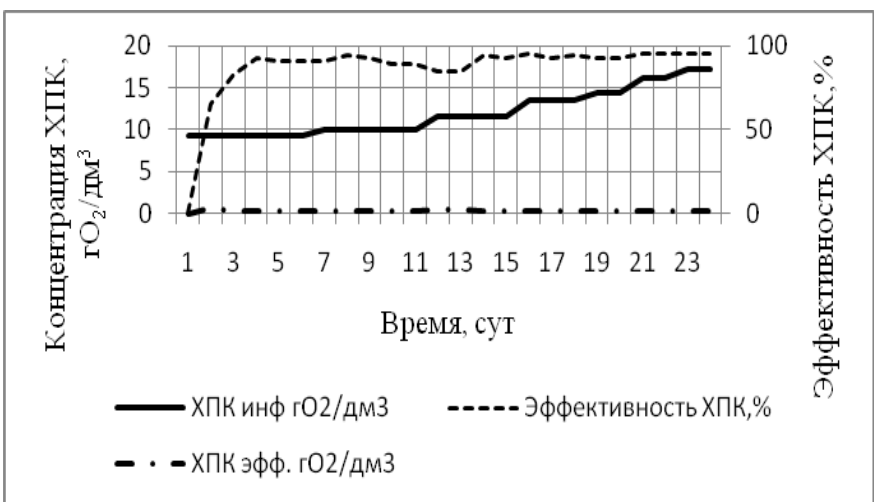

Рис. 1. Изменение эффективности снижения ХПК в UASB-реакторе

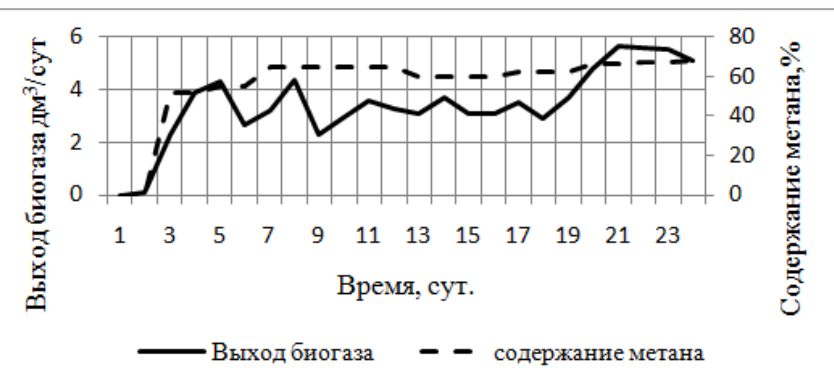

Рис. 2. Процесс образования биогаза и содержание метана в UASB-реакторе 
Таким образом, было доказано, что UASBреакторы являются оптимальным техническим решением для утилизации сточных вод предприятий первичного виноделия.

\section{5. Апробация результатов исследований}

Результаты полученных исследований были испытаны в качестве пилотного проекта на научнопроизводственном предприятии «Агромир», Илличевский район, Одесса. Процесс очистки сточных вод проводился согласно схеме 1 на рис.3.

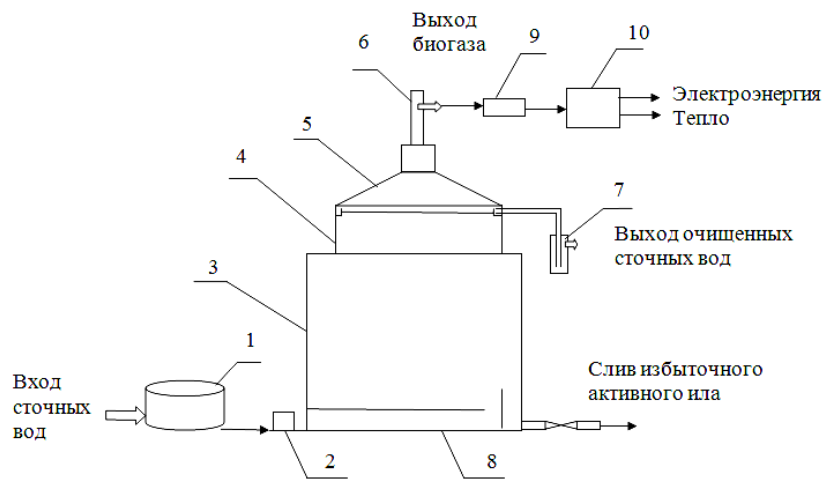

Рис. 3. Схема сбраживания сточных вод в UASB-реакторе: 1 - резервуар-накопитель; 2 - насос; 3 - камера сбраживания метантенке; 4 - камера накопления очищенных сточных вод; 5 - сборная камера; 6 - газовая труба; 7 - трубопровод для отвода очищенных сточных вод; 8 - распределительный коллектор; 9 - аппарат высушивания биогаза; 10 - когенерационная установка

Сточные воды с осадком подают в резервуарнакопителя 1 куда же загружают измельчении гребни винограда и перегной крупного рогатого скота. Полученную таким образом смесь насосом 2 через распределительный коллектор 8 перекачивают в камеру сбраживания метантенке 3 . Сбраживание происходит в течение 1,5-4 суток, при температуре 35-37 ${ }^{\circ} \mathrm{C}$ и $\mathrm{pH}=6,8-7,2$ с образованием пузырьков биогаза, которые поднимаются вверх в сборную камеру 5 и поступают через газовую трубу 6 в аппарат для высушивания биогаза 9, а затем в установку комбинированной 10. Отвод сточных вод осуществляется через трубопровод 7.

\section{6. Выводы}

В результате проведенных исследований можно сделать следующие выводы:

- Анаэробные способы обработки сточных вод обладают существенными преимуществами по сравнению с аэробными, а именно: компактностью, надежностью, низким приростом активного ила, и проблем, связанных с его утилизацией, низкими капитальными и эксплуатационными затратами.

- На основе приведенных исследований (снижения значения ХПК и образования биогаза) доказано, что оптимальным техническим решением для очистки сточных вод является UASB-реактор.
- Приведена схема сбраживания сточных вод в UASB-реакторе.

\section{Литература}

1. Калюжный, C. В. Высокоинтенсивные анаэробные биотехнологии очистки промышленных сточных вод [Текст] / С. В. Калюжный // Катализ в промышленности.- 2004.- № 6. - С. 42-50.

2. Катраева, И. В. Современные анаэробные препараты для очистки концентрированных сточных вод [Текст] / И. В. Катраева // Водоснабжение, канализация, строительные системы водных ресурсов.- 2011.- № 2(16).- С. 179-184.

3. Калюжный, С. В. Анаэробная биологическая очистка сточных вод [Текст] / С. В. Калюжный, Д. А. Данилович, А. Н. Ножевникова // Итоги науки и техники.- 1991.- № 29. - 155 с.

4. Крусир, Г. В. Перспективы использования дрожжевых осадков винодельческих предприятий [Текст] / Г. В. Крусир, И. Ф. Соколова // Экологическая безопасность.- 2013. - №16.C. 111-114.

5. Lettinga, G. Use of the Upflow sludge blanket (USB) reactor concept for biological wastewater treatment [Text] / G. Lettinga, A. F. M. Velsen, S. W. Hobma, W. Zeeuw, A. Klapwijk // Especially for Anaerobic Treatment. Biotechnology and Bioengineering.- 1980.- № 22.- P. 699-734.

6. Fang, H. H. P. Degradation of phenol in wastewater in an upflow anaerobic sludge blanket reactor chem [Text] / H. H. P. Fang, T. Li, H-K. Chui // Water research. - 1996. - № 30.- P. 1353-1360.

7. Долина, Л. Ф. Реакторы для очистки сточных вод [Текст] / Л. Ф. Долина // Днепропетровск.- 2001.$80 \mathrm{c}$.

\section{References}

1. Kalyuzhny, S. V. (2004). Highly-intensive anaerobic biotechnologies of industrial wastewater treatment. Catalysis in Industry, 6, 42-50.

2. Katraeva, I. V. (2011). Modern anaerobic preparations purification concentrated wastewater. Water, sanitation, building water system, 2 (16), 179-184.

3. Kalyuzhny, S. V., Danilovich, D. A., Nozhevnikova, A. N. (1991). Anaerobic biological treatment of wastewater. Results in science and technology, 29, 155.

4. Sokolova, I. F., Krusir, G. V. (2013). Prospects for the use of yeast sediments wineries. Environmental Safety, 16, 111-114.

5. Lettinga, G., Velsen, A. F. M., Hobma, S.W., De Zeeuw, W., Klapwijk, A. (1980). Use of the Upflow Sludge Blanket (USB) Reactor Concept for Biological Wastewater Treatment, Especially for Anaerobic Treatment. Biotechnology and Bioengineering, 22, 699-734.

6. Fang, H. H. P., Chen, T., Li, Y-Y., Chui, H-K. (1996). Degradation of Phenol in Wastewater in an Upflow Anaerobic Sludge Blanket Reactor. Water Research, 30, 1353-1360.

7. Dolyna, L. F. (2001). Reactors for wastewater treatment. Dnepropetrovsk, 80. 
Крусир Галина Всеволодовна, доктор технических наук, профессор, кафедра экологии пищевых продуктов и производств, Одесская национальная академия пищевых технологий, ул. Канатная, 112, г. Одесса, Украина,

E-mail: krussir_65@mail.ru

Соколова Ирина Федоровна, аспирант, кафедра экологии пищевых продуктов и производств, Одесская национальная академия пищевых технологий, ул. Канатная, 112, г.Одесса, Украина,

E-mail: kukuler4ik@mail.ru

\title{
УДК 338.244:504.453
}

\section{РОЗРОБКА МЕТОДУ ОЦНКИ НЕБЕЗПЕКИ ЗСУВІВ НА ДІЛЯНКАХ АВТОМОБІЛЬНИХ ДОРІГ В УМОВАХ НЕЧІТКОЇ ІНФОРМАЦІЇ}

\author{
(C) Л. І. Нефьодов, Н. Ю. Філь
}

Проаналізовані фактори небезпеки зсувів на ділянках автомобільних доріг. Розглянуто основні етапи методу нечіткого виводу. Розроблено метод оцінки небезпеки зсувів на ділянках автомобільних доріг $в$ умовах нечіткої інформації. Наведено приклад оцінки факторів небезпеки зсувів на ділянках автомобільних доріг в умовах нечіткої інформачї у середовищі Matlab.

Ключові слова: зсуви, небезпека, дорога, метод, нечіткість, фаззифікація, дефаззіфікація, Мамдані.

Factors of landslide hazard on areas of highways have been analyzed. The main steps of fuzzy inference method are described. The method of landslide hazard assessment on areas of highways in terms of fuzzy information has been developed. The example of landslide hazard assessment on areas of highways in terms of fuzzy information in Matlab has been provided.

Keywords: landslides, hazard, road, method, fuzzy, fuzzification, defuzzification Mamdani.

\section{1. Ветуп}

Незбалансована та безсистемна господарська діяльність створила реальні передумови для активного розвитку природних екзогенних геологічних процесів (ЕГП), серед яких найбільш руйнівними є зсуви, що розвинені сумісно 3 абразією на узбережжя морів та лиманів, перебудовою берегів водосховищ, селів у горах та передгір'ях, ерозією по берегах річок та схилах балок [1].

Залучення територій з розвитком природних ЕГП до сфери господарської діяльності призводить до неминучих змін навколишнього середовища, що супроводжуються техногенним посиленням природного перебігу процесів, особливо в місцях розташування потенційно небезпечних об'єктів. Безпека життєдіяльності населення та численних господарських об'єктів у районах розвитку небезпечних природних та природно-техногенних процесів $€$ однією 3 основних соціальноекологічних проблем сьогодення [2, 3].

Упродовж 2012-13 років до числа найбільш небезпечних ЕГП за збитками завданими господарським об'єктам, належать зсуви, підтоплення, карст, абразія, переробка берегів водосховищ та осідання земної поверхні над гірничими виробками $[4,5]$.

Господарська діяльність, відсутність належних інженерних та екологічних заходів щодо освоєння територій спричиняє активне поширення зсувів на території населених пунктів, що створює загрозу безпеці життєдіяльності населення, інфраструктурі та території в цілому.

Кількість зсувів складає близько 30 тисяч i постійно змінюється за рахунок ліквідації (зрізання, зчищення), злиття чи формування нових зсувів під впливом природних и техногенних факторів [4, 5].

Найбільшого розвитку зсувні процеси набули на узбережжі Азовського моря, на схилах водосховищ Дніпровського каскаду та річкових долин в Львівській, Івано-Франківській, Закарпатській, Одеській, Київській та Черкаській областях $[1,4]$.

У долинах великих річок та на їх схилах розташовані міста, які зазнають збитків від дії зсувів, а саме Київ, Дніпродзержинськ, Дніпропетровськ, Запоріжжя, Чернігів, Полтава, Чернівці та інші. Активна господарська діяльність викликала поширення зсувів у більш ніж 200 містах і селищах міського типу [4, 5].

Площа поширення ділянок 3 розвитком зсувів у межах міських територій складає близько

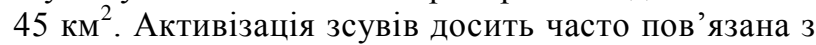
розвитком супутніх процесів - ерозійного та абразійного, які підсилюють розвиток основного процесу [4, 5]. Серед домінуючих природних чинників активізації слід виділити:

- гідрологічні (підняття рівнів та зміна витрат води в поверхневих водотоках, рівні води та хвильовий режим морів, озер, інших водойм та абразійна дія поверхневих вод та відповідний підмив та розлив язикових частин зсувів); 